\title{
A Rare Case of Peripheral PNET with A Rare Presentation
}

Authors

\section{Dr Pushkraj Baswant Birajdar, DNB Neurosurgery ${ }^{1}$, Dr T.Narsimha Rao, Mch Neurosurgery ${ }^{2}$}

${ }^{1}$ Consultant Neurosurgeon, Government Medical College, Latur-413512, Maharashtra

${ }^{2}$ Senior Consultant Neurosurgeon, Care Hospital, Hyderabad-01

Email: nthiriveedi@yahoo.com

Corresponding Author

\section{Dr Pushkraj Baswant Birajdar}

C/o B.S.Birajdar, Sakar House, Near Jaikranti College, Sitaramnagar, Latur-413512, Maharashtra

Email: pushkrajb@gmail.com

\begin{abstract}
A 28 year male without any comorbidity having fever since 2 weeks and complex partial seizures since day 1 was presented with altered sensorium with left sided hemiparesis in emergency room and evaluated with MRI Brain which s/o Right fronto-temporal bleed with mass effect. Emergency Right sided Decompression Craniotomy done, intraoperative temporal lobe having mass lesion with clot around it; total excision of mass with clot evacuated. On histopathology and IHC study show its rare case of Peripheral PNET lesion. Postop period uneventful.
\end{abstract}

Key Words: Hemiparesis, P-PNET, Craniotomy, Round Cells, Synaptophysin.

\section{Introduction}

History: A 28 year old male presented with Fever since 2 weeks on-off episodes, seizures involving right side of body since 2 weeks, on medications, altered sensorium since 1 day. Not significant family or past history.

Examination: Drowsy, arousable, febrile 100.4 F. GCS E2 V2 M5, Pupils B/L ERTL, Left side Hemiparesis, vitals stable.

Investigations: All routine blood investigations, chestxray were apparently

Normal.
CT scanbrain \& MRI BRAIN have been done s/o Right temporal SOL with haemorrhages inside with mass effect? Glioblastoma Multiforme? Cavernoma with bleed? AVM.

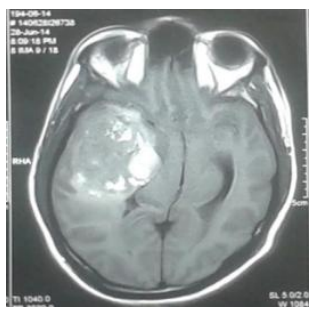

Fig.1:T1 image

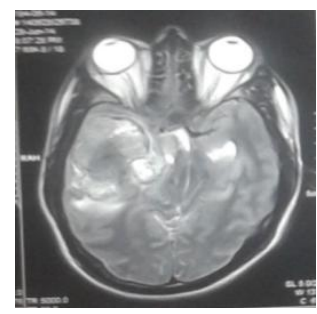

Fig.2: T2 image 


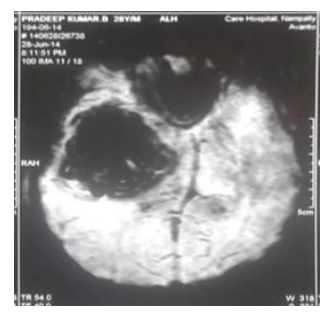

Fig.3: GRE image

\section{Management}

After evaluation, patient under went right Fronto Temporo Parietal Decompressive Craniotomy and evacuation of hematoma with lesion. Procedure and post-operative course was uneventful. Patient recovered well after surgery and gain full consciousness with left hemiparesis which improved with time.

\section{Histopathology}

H \& E Stain: Small round blue cells neoplasm with primitive appearing and some neuronal differentiated cells with mitotic figures.

Positivity with Synaptophysin: A marker of neuronal cells

GFAP: Negative for GFAP-glialorigin

EMA: Negative for EMA -ependymal cellorigin

Ki-67index: (a cellular marker for proliferation) 30$40 \%$

Strong Membranous Positivity with CD 99

Friend leukemia integration 1transcription gene

(FLI 1): Expression of this gene is highly specific for P-PNET

Finally IHC \& Histology features are diagnostic of Peripheral PNET.
Cause: Loss of the short arm of chromosome 17 (17p13.3) is the most frequent abnormality.

\section{Conclusions}

P-PNET is very rare presentation in our clinical practice \& prognosis will be decided on chromosomal study \& histology study.

\section{References}

1. Hasegawa SL, Fletcher CD. Primary cutaneous Ewing's sarcoma: Immunophenotypic \& molecular cytogenetic evaluation of five cases. Am J Surg Pathol 1998;22:310-8.

2. Kouyialis AT, Sakas DE: Primitive supratentorial neuroectodermal tumor in an adult. J Clin Neurosci. 2005, 12 (4): 492495. 10.1016/j.jocn.2004.07.014.

3. Zainab A Al Jufairi, Amarjit K Sandhu, Sara Mathew George : Management of Primitive Neuro-ectodermal Tumor of the Vagina in a Sickle cell disease Patient. Bahrain Med Bull; 2011; 33(4)

4. Bancalari E,de Alava E,Tardio JC. Primary Vaginal Ewing Sarcoma: Case Report and Review of the Literature: Int J Surg Pathol ;October 2012;20(3):305-10

5. Chi-man Yip, Shu-Shong hsu, Nai-Jen Chang, Jyh-seng Wang,Wei-Chaun Liao, Jun-Yih Chen et al::Primary vaginal Extraosseous Ewing's sarcoma/Primitive Neuroectodermal tumor with cranial metastasis.Case report. J Chin Med Assoc; 2009;72(6):332-35.

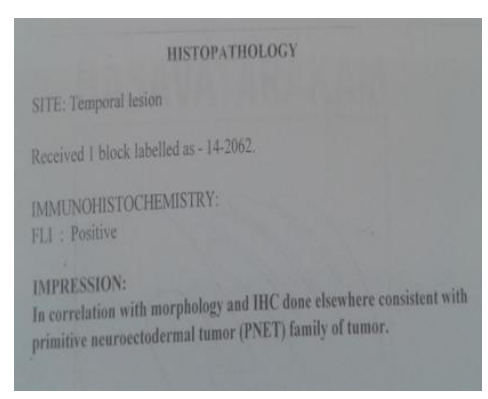

Fig.4: IHC Study 